\title{
Article \\ A Method for Determining the Workability Diagram by Varying Friction Conditions in the Upsetting of a Cylinder between Flat Dies
}

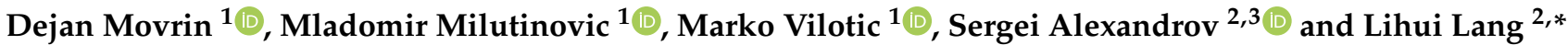 \\ 1 University of Novi Sad, Faculty of Technical Sciences, Trg Dositeja Obradovića 6, 21000 Novi Sad, Serbia; \\ movrin@uns.ac.rs (D.M.); mladomil@uns.ac.rs (M.M.); markovil@uns.ac.rs (M.V.) \\ 2 School of Mechanical Engineering and Automation, Beihang University, 37 Xueyuan Road, \\ Beijing 100191, China; sergei_alexandrov@spartak.ru \\ 3 Federal State Autonomous Educational Institution of Higher Education, South Ural State \\ University (National Research University), 76 Lenin Prospekt, 454080 Chelyabinsk, Russia \\ * Correspondence: lang@buaa.edu.cn; Tel.: +86-10-82316821
}

check for updates

Citation: Movrin, D.; Milutinovic, M.; Vilotic, M.; Alexandrov, S.; Lang, L. A Method for Determining the Workability Diagram by Varying Friction Conditions in the Upsetting of a Cylinder between Flat Dies. Crystals 2021, 11, 1411. https:// doi.org/10.3390/cryst11111411

Academic Editors: Jana Petru and Marek Pagáč

Received: 19 October 2021

Accepted: 9 November 2021

Published: 18 November 2021

Publisher's Note: MDPI stays neutral with regard to jurisdictional claims in published maps and institutional affiliations.

Copyright: (C) 2021 by the authors Licensee MDPI, Basel, Switzerland. This article is an open access article distributed under the terms and conditions of the Creative Commons Attribution (CC BY) license (https:// creativecommons.org/licenses/by/ $4.0 /)$.

\begin{abstract}
This paper aims to develop a method for determining the workability diagram by varying frictional conditions in the cylinder upsetting test. The method is based on a known theoretical relationship between the average stress triaxiality ratio and in-surface strains if the initiation of fracture occurs at a traction-free surface. This relationship is valid for any rigid/plastic strain hardening material obeying the Mises-type yield criterion and its associated flow rule, which shows the wide applicability of the method. The experimental input to the method is the strain path at the site of fracture initiation. Neither experimental nor numerical determination of stress components is required at this site, though the general ductile fracture criterion involves the linear and quadratic invariants of the stress tensor. The friction law's formulation is neither required, though the friction stress is the agent for varying the state of stress and strain at the site of ductile fracture initiation. The upsetting tests are carried out on normalized medium-carbon steel C45E, for which the workability diagram is available from the literature. Comparison of the latter and the diagram found using the new method shows that the new method is reliable for determining a certain portion of the workability diagram.
\end{abstract}

Keywords: ductile fracture; workability diagram; upsetting; friction

\section{Introduction}

Empirical ductile fracture criteria have been successfully used to predict fracture initiation in metal forming processes for several decades (see [1-5] among many others). Usually, such criteria involve several constitutive parameters that should be identified using experimental or hybrid experimental-numerical approaches. The functions that contain these parameters are specified before testing. For example, the predictive capacity of several specified functions has been compared in [6,7]. It is evident that the result of such comparisons depends on the material tested. An advantage of the fracture criterion based on the workability diagram and an average stress triaxiality ratio is that this criterion involves an arbitrary function rather than arbitrary parameters [8]. This function is determined in the course of ductile fracture testing. Therefore, any set of experimental data can be approximated with any accuracy if the effect of the cubic stress invariant on the initiation of fracture is negligible. To increase the accuracy of the criterion, one has to design experiments to cover a wide range of the stress triaxiality ratio at the site of fracture initiation.

The upsetting of a specimen between two dies is a widely used method for identifying ductile fracture criteria. The Rastegaev test can be regarded as one of the basic tests. A description of this test is provided in [9]. The deformation is almost homogeneous in 
the Rastegaev test. A circular solid cylinder is used as the specimen in the original test. However, the general methodology applies to specimens of other geometries [10]. To vary the state of stress at the fracture initiation site, one can vary the initial shape of specimens and/or the shape of dies. In particular, the collar test is widely used for identifying ductile fracture criteria (for example, [10-12]). Specimens of hexagonal and square cross-sections have been designed and tested in [11,13], respectively. Notched cylinders have been used in $[14,15]$. Using various profiled dies, the upsetting process has been adopted for identifying ductile fracture criteria in [16-19].

The present paper proposes to vary friction conditions to vary the state of stress at the fracture initiation site. The efficiency of the method is demonstrated using the upsetting of circular solid cylinders between flat dies. However, it is straightforward to combine this method with the above methods developed for varying the state of stress at the fracture initiation site.

Real boundary conditions are essential for calibrating ductile fracture criteria using experimental-numerical methods [20]. Of course, friction cannot be regarded as such a boundary condition. Nevertheless, standard procedures for identifying ductile fracture criteria require numerical simulations $[6,7,21]$, which is impossible without specifying a friction law. An advantage of the method used in the present paper is that no numerical simulation is required. Moreover, the specific friction law is not required for this method. It is only important to vary friction conditions significantly. These conditions affect the state of stress at the fracture initiation site. However, the average stress triaxiality ratio involved in the ductile fracture criterion under consideration is expressed in terms of in-surface strains if fracture initiation occurs at a traction-free surface [22]. Several experimental methods are available to measure in-surface strains with good accuracy $[10,23]$. No theoretical method other than the relationship developed in [22] is required. This relationship is valid for any hardening law. A similar relationship is available for orthotropic materials under plane stress conditions [24]. However, it has been derived assuming proportional strain paths. This reduced form of the relationship has also been used for isotropic materials in [21].

Numerical methods are usually used to determine the evolution of the average stress triaxiality throughout the process of deformation $[25,26]$. The relationship proven in [22] significantly facilitates identifying ductile fracture criteria based on this quantity and increases the accuracy of the final result since the boundary conditions involved in numerical simulations do not affect the relationship [22].

The method developed applies to any strain hardening material that obeys the von Mises yield criterion and its associated flow rule.

\section{Theoretical Basis}

The simplest workability diagram provides the dependence of the strain to fracture on the stress triaxiality, assuming that the strain path is proportional [27]. The following equation represents this dependence:

$$
\varepsilon_{e q}^{f}=\Phi(\beta) .
$$

Here, $\varepsilon_{e q}^{f}$ is the equivalent strain to fracture, $\beta=3 \sigma / \sigma_{e q}$ is the stress triaxiality ratio, $\sigma$ is the hydrostatic stress, and $\sigma_{e q}$ is the equivalent stress. Additionally,

$$
\sigma=\frac{\sigma_{i j} \delta_{i j}}{3}, \sigma_{e q}=\sqrt{\frac{3}{2}} \sqrt{\left(\sigma_{i j}-\sigma \delta_{i j}\right)\left(\sigma_{i j}-\sigma \delta_{i j}\right)}, \xi_{e q}=\sqrt{\frac{2}{3}} \sqrt{\xi_{i j} \xi_{i j}}, \varepsilon_{e q}=\int_{0}^{t} \xi_{e q} d \tau .
$$

Here, $t$ is the time, $\sigma_{i j}$ are the stress components, $\xi_{i j}$ are the strain rate components, $\delta_{i j}$ is the Kronecker symbol, $\xi_{e q}$ is the equivalent strain rate, and the integral should be evaluated over the strain path. The fracture criterion based on the workability diagram reads [8]

$$
\varepsilon_{e q}^{f}=\Phi\left(\beta_{a v}\right)
$$


where $\beta_{a v}$ is the average stress triaxiality ratio defined as

$$
\beta_{a v}=\frac{1}{\varepsilon_{e q}} \int_{0}^{t} \beta \xi_{e q} d \tau .
$$

The integral here should be evaluated over the strain path.

In general, it is difficult to determine $\beta_{a v}$ experimentally. However, ductile fracture often initiates on traction-free surfaces. In this case, Equation (4) simplifies to [22]

$$
\beta_{a v}=\frac{2\left(\varepsilon_{1}+\varepsilon_{2}\right)}{\varepsilon_{e q}} .
$$

Here, $\varepsilon_{1}$ and $\varepsilon_{2}$ are the principal logarithmic in-surface strains. It is relatively easy to measure these strains experimentally. Then, no theoretical solution is required to apply Equation (3) if the function $\Phi$ is known. Alternatively, one can combine experimental results with Equations (1) and (3) to determine a portion of the workability diagram corresponding to the available experimental data.

Equation (5) is valid for rigid plastic materials obeying the yield criterion $\sigma_{e q}=\sigma_{0} \Omega\left(\varepsilon_{e q}\right)$ and its associated flow rule. Here, $\Omega\left(\varepsilon_{e q}\right)$ is an arbitrary function of its argument satisfying the conditions $\Omega(0)=1$ and $d \Omega / d \varepsilon_{e q} \geq 0$ for all $\varepsilon_{e q}$, and $\sigma_{0}$ is the tensile yield stress at $\varepsilon_{e q}=0$.

\section{Design of Experiment}

Four upsetting tests have been designed. A schematical diagram of a generic test is shown in Figure 1, where $F$ is the compression force and $V$ is the speed of the upper die. The initial specimen for each test is a circular solid cylinder of diameter $20 \mathrm{~mm}$ and height of $24 \mathrm{~mm}$. The tests are classified by the type of lubricant and the quality of the friction surface. The friction surface has been turned or ground.

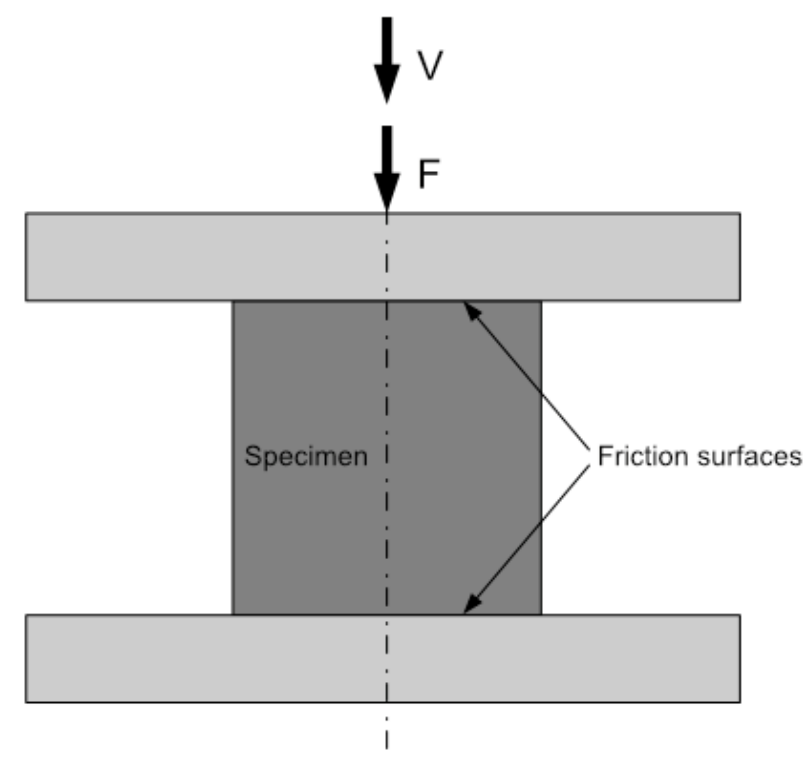

Figure 1. Schematic diagram of a generic test.

Teflon (polytetrafluoroethylene PTFE) or mineral oil have been used as lubricants. Some specimens have been upset with no lubricant. Table 1 shows the used combinations of the types of lubricant and surface treatment. The table is self-explanatory. The tests have been conducted on a Sach and Kieselbach hydraulic press with a capacity of $6.3 \mathrm{MN}$ at room temperature and $V=0.1 \mathrm{~mm} / \mathrm{s}$. 
Table 1. Upsetting test conditions.

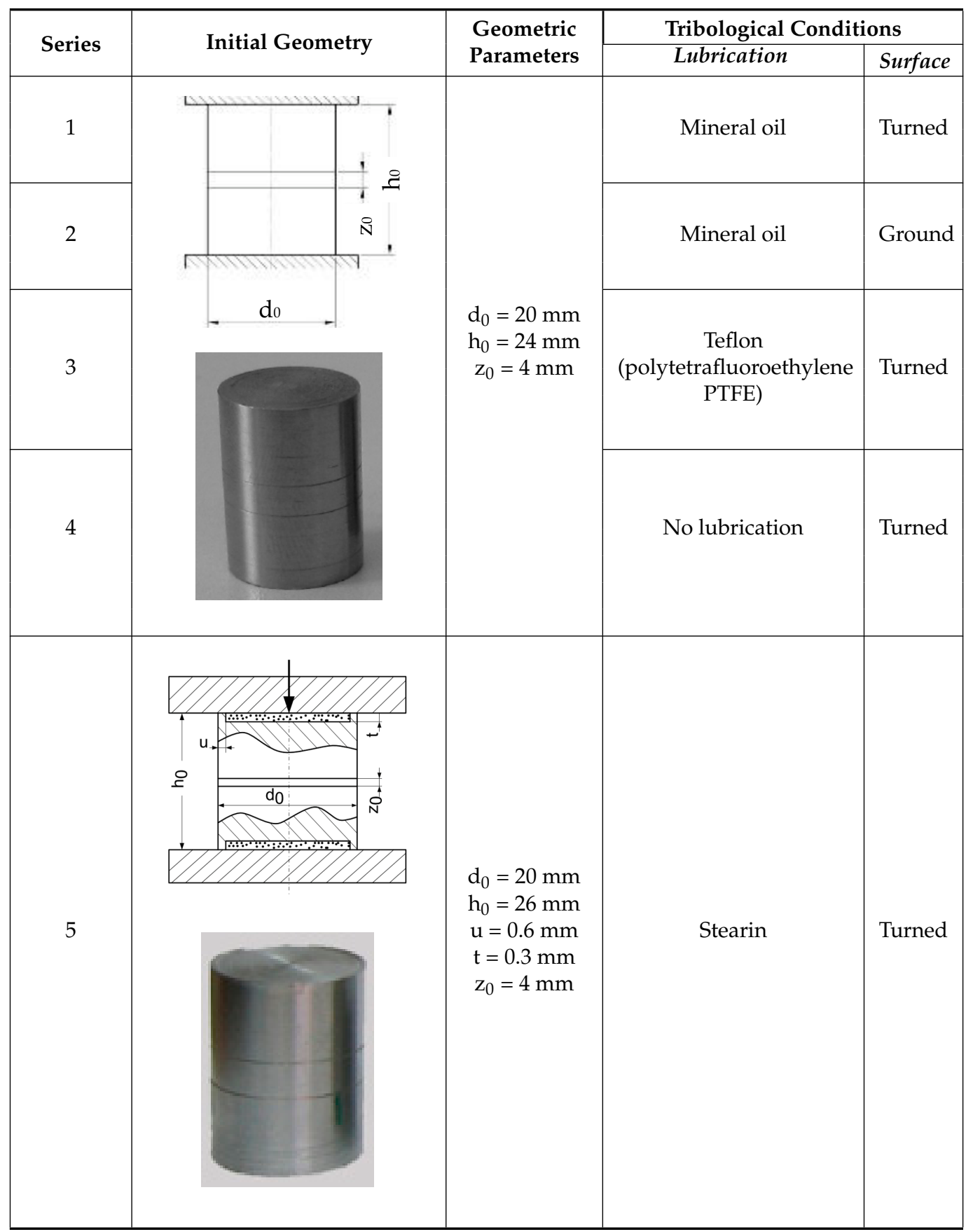

Before testing, it was guessed that fracture would initiate on the lateral surface in the vicinity of the plane of symmetry of the specimen. The experiment has confirmed this guess. In this case, the principal strains involved in Equation (5) are the circumferential and axial strains. The circumferential strain can be determined by measuring the diameter of the specimen at the intersection of its lateral surface and plane of symmetry. Let $d_{f}$ be this diameter at the instant of fracture initiation. Then, the circumferential strain at the instant of fracture initiation is

$$
\varepsilon_{\theta}^{f}=\ln \frac{d_{f}}{d_{0}} .
$$


Here, $d_{0}$ is the initial diameter of the cylinder. To measure the axial strain, two grid lines have been applied at mid-height. The initial distance between the lines is $z_{0}=4 \mathrm{~mm}$. Then, the axial strain at the instant of fracture initiation is

$$
\varepsilon_{z}^{f}=\ln \frac{z_{f}}{z_{0}} .
$$

Here, $z_{f}$ is the distance between the grid lines at the instant of fracture initiation. Using Equations (6) and (7), one rewrites Equation (5) as

$$
\beta_{a v}^{f}=\frac{2\left(\varepsilon_{\theta}^{f}+\varepsilon_{z}^{f}\right)}{\varepsilon_{e q}^{f}} .
$$

Here, $\beta_{a v}^{f}$ and $\varepsilon_{e q}^{f}$ are $\beta_{a v}$ and $\varepsilon_{e q}$ at the instant of fracture initiation, respectively.

In addition to the tests above, the Rastegaev test has been carried out. Stearin has been used as a lubricant. Table 1 shows the essential geometric parameters of the specimen.

In total, five series of tests shown in Table 1 have been conducted. Each series has included testing of three nominally identical specimens. The values of $d_{f}$ and $z_{f}$ have been measured at several locations of each specimen. The arithmetic mean of these values has been used in Equations (6) and (7).

To find $\varepsilon_{\theta}^{f}$ and $\varepsilon_{z}^{f}$ using Equations (6) and (7), one needs to measure $d_{f}$ and $z_{f}$ at the instant of fracture initiation. However, it is besides necessary to evaluate the integral in Equation (2) for determining $\varepsilon_{e q}^{f}$ involved in Equation (8). For this reason, the upsetting tests have been carried out incrementally. Each increment of the die's displacement is approximately equal to $10 \%$ of the current height of the specimen. This procedure allows for producing the strain path as a discrete function. Then, one can approximate this function with a continuous function and evaluate the integral in Equation (8) with no difficulty.

The nominal chemical composition of this steel is shown in Table 2.

Table 2. Chemical composition of steel C45E.

\begin{tabular}{cccccccccc}
\hline Chemical Element & $\mathbf{C}$ & Si & Mn & P & S & Cr & Mo & Ni & Cu \\
\hline Content $(\%)$ & 0.46 & 0.23 & 0.64 & 0.008 & 0.022 & 0.18 & 0.02 & 0.08 & 0.17 \\
\hline
\end{tabular}

\section{Experimental Results}

The specimens have been made of normalized medium-carbon steel C45E (EN standard) with the microstructure consisting of ferrite grains and pearlite colonies.

The shape of specimens at the instant of fracture initiation is illustrated in Figure 2.

\begin{tabular}{|l|l|l|l|l|}
\hline Series 1 & Series 2 & Series 3 & Series 4 & Series 5 \\
\hline & & & \\
& & & \\
& & & \\
\hline
\end{tabular}

Figure 2. Shape of specimens at the instant of fracture initiation.

Typical geometric changes after each increment of the die's displacement are shown in Figure 3 for series 5. 


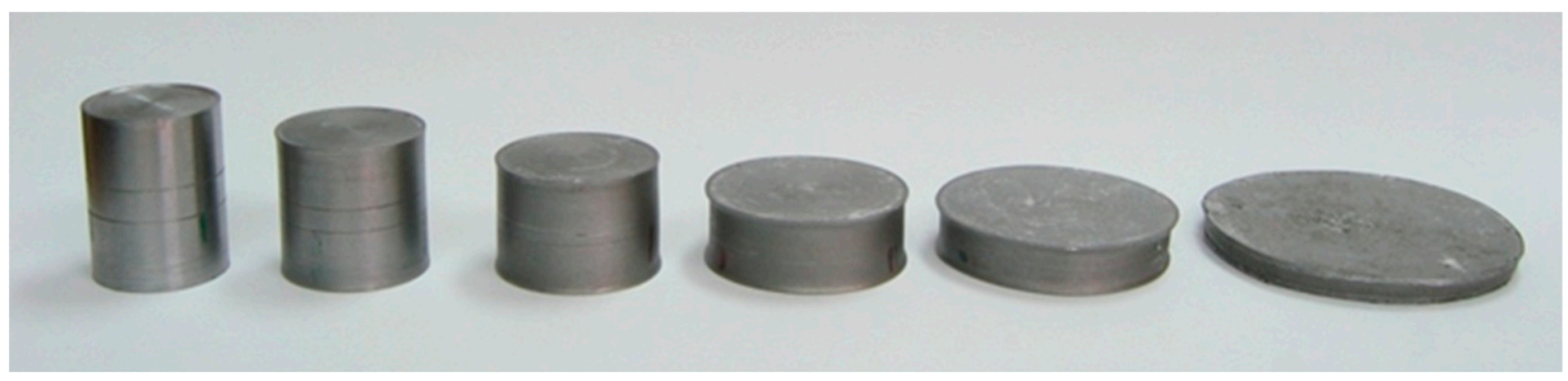

Figure 3. Typical geometric changes after each increment of the die's displacement (Series 5).

The experimental strain paths determined in five series of the upsetting process (Table 1) according to the procedure described in the previous section are depicted in Figure 4. The leftmost points correspond to the instant of fracture initiation. The corresponding values of $\varepsilon_{\theta}^{f}$ and $\varepsilon_{z}^{f}$ are presented in Table 3. An optical microscope (Leitz Orthoplan) has been used for measuring the distance between the grid lines. Some specimens are significantly squeezed at the instant of fracture initiation (for example, the rightmost image in Figure 3). Nevertheless, the grid lines are clearly visible, which allows for measuring $z$ with the same accuracy independently of the stage of the process. An example is illustrated in Figure 5, where a specimen of Series 5 is shown.

Table 3. Circumferential and axial strains at the instant of fracture initiation.

\begin{tabular}{cccccc}
\hline Series & $\mathbf{1}$ & $\mathbf{2}$ & $\mathbf{3}$ & $\mathbf{4}$ & $\mathbf{5}$ \\
\hline$\varepsilon_{\theta}^{f}$ & 0.82 & 0.752 & 0.961 & 0.725 & 0.92 \\
\hline$\varepsilon_{z}^{f}$ & -1.082 & -0.867 & -1.426 & -0.735 & -1.74 \\
\hline
\end{tabular}
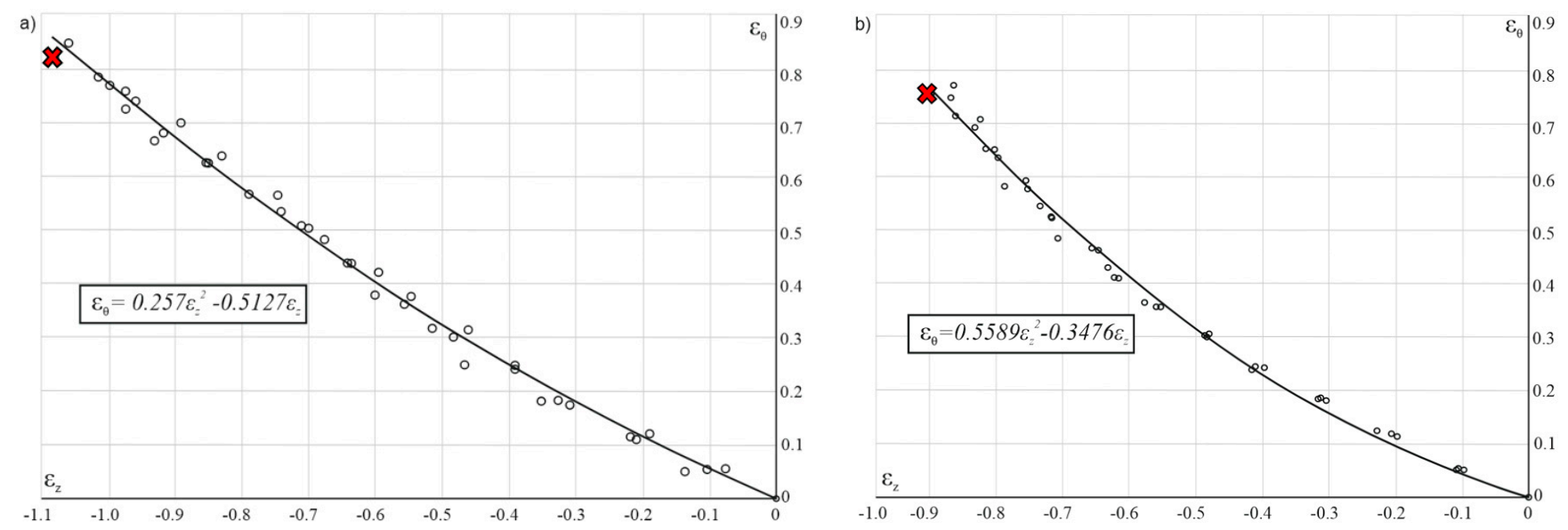

Figure 4. Cont. 

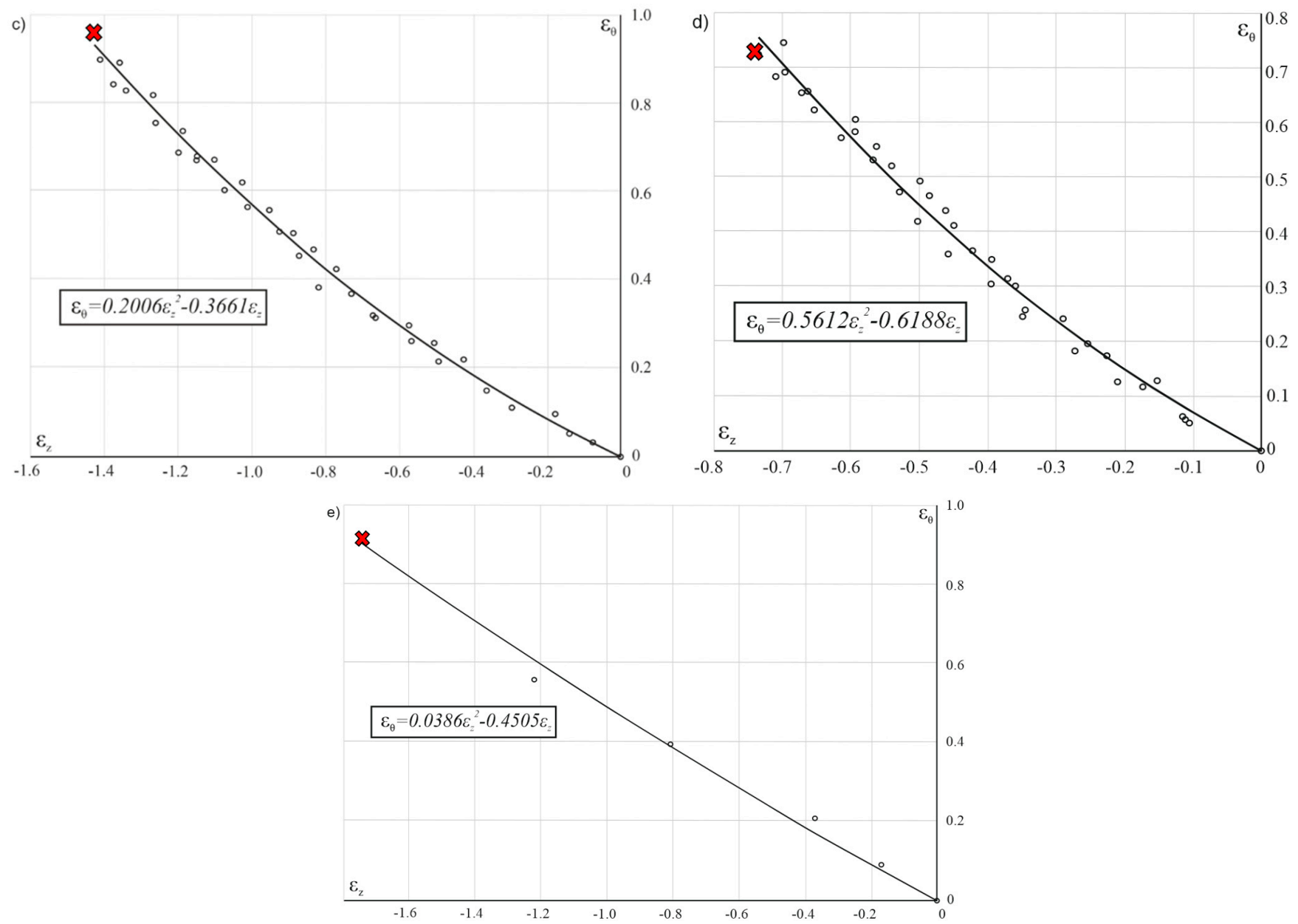

Figure 4. Strain paths at the site of fracture initiation: (a)—series 1, (b)—series 2, (c)—series 3, (d)—series 4, (e)—series 5.

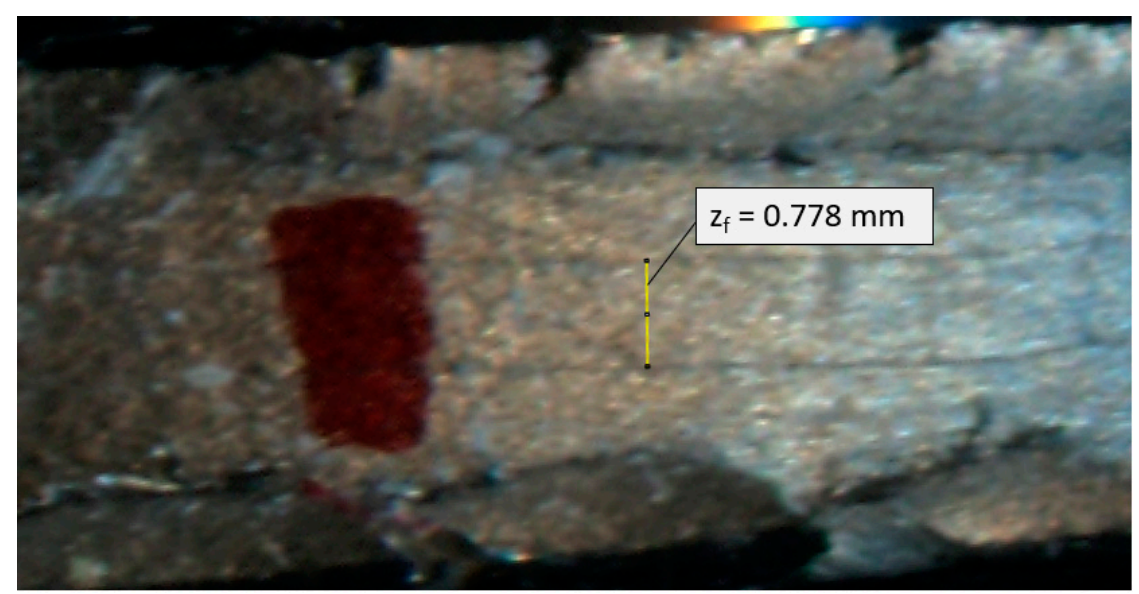

Figure 5. Illustration of measuring $z_{f}$ in a specimen of Series 5.

\section{Workability Diagram}

All the curves in Figure 4 are slightly concave down, suggesting that quadratic polynomials are appropriate for interpolating these experimental data. In addition, $\varepsilon_{\theta}=0$ for $\varepsilon_{z}=0$. Therefore, the generic form of approximating functions is

$$
\varepsilon_{\theta}=B \varepsilon_{z}^{2}+A \varepsilon_{z}
$$


The coefficients $A$ and $B$ have been found using the method of least squares (Table 4). The corresponding curves are shown in Figure 4 by solid lines. Taking into account the equation of incompressibility and Equation (9), one can rewrite the integral in Equation (2) as (see, for example, [10])

$$
\varepsilon_{e q}^{f}=-\frac{2}{\sqrt{3}} \int_{0}^{\varepsilon_{z}^{f}} \sqrt{\left(A+2 B \varepsilon_{z}\right)^{2}+2 B \varepsilon_{z}+A+1} d \varepsilon_{z} .
$$

Table 4. Coefficients A and B involved in Equation (9).

\begin{tabular}{cccccc}
\hline Series & $\mathbf{1}$ & $\mathbf{2}$ & $\mathbf{3}$ & $\mathbf{4}$ & $\mathbf{5}$ \\
\hline $\mathrm{A}$ & -0.5127 & -0.3476 & -0.3661 & -0.6188 & -0.4505 \\
\hline $\mathrm{B}$ & 0.257 & 0.5589 & 0.2006 & 0.5612 & 0.0386 \\
\hline
\end{tabular}

Using the data from Tables 3 and 4, one can evaluate this integral numerically. The result of this integration is presented in Table 5 . The data from Tables 4 and 5 combine with Equation (8) to provide $\beta_{a v}^{f}$. These $\beta_{a v}^{f}$-values and the corresponding $\varepsilon_{e q}^{f}-$ values from Table 5 allow for finding five points of the workability diagram. These points are shown in Figure 6. Since $\beta_{a v}^{f}=0$ in the torsion test, it is seen from this figure that series 4 can replace this test.

Table 5. Equivalent strain at the instant of fracture initiation.

\begin{tabular}{cccccc}
\hline Series & $\mathbf{1}$ & $\mathbf{2}$ & $\mathbf{3}$ & $\mathbf{4}$ & $\mathbf{5}$ \\
\hline$\varepsilon_{e q}^{f}$ & 1.15 & 0.95 & 1.47 & 0.85 & 1.74 \\
\hline
\end{tabular}

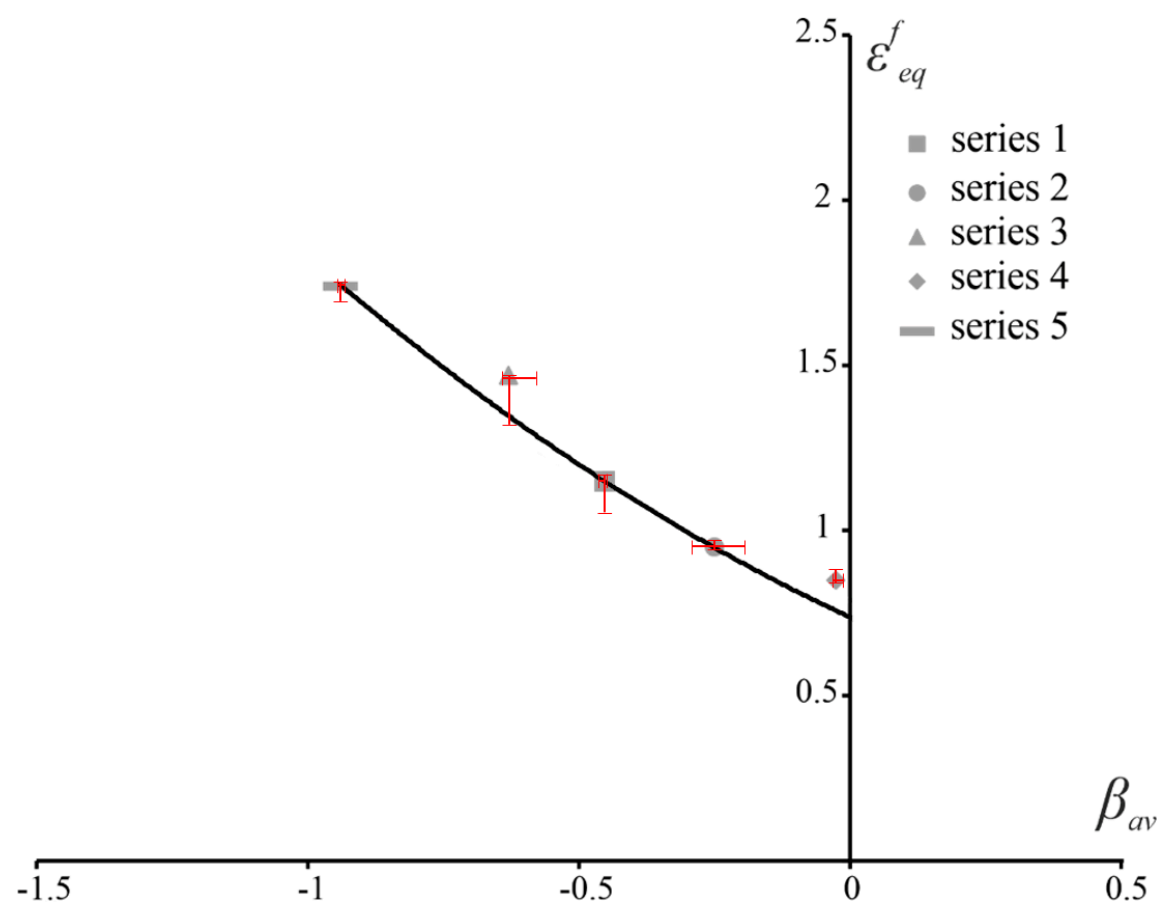

Figure 6. Workability diagram for C45E steel.

The workability diagram for C45E steel has been determined in [18] using another method. The following equation approximates this diagram:

$$
\varepsilon_{e q}^{f}=0.33 \cdot \beta_{a v}^{2}-0.75 \cdot \beta_{a v}+0.75 .
$$


The curve corresponding to Equation (11) is depicted in Figure 6. It is seen that the experimental points determined in the present paper lie on the workability diagram from [18], which confirms that the method proposed is reliable.

\section{Conclusions}

A new method for determining the workability diagram using the fracture criterion (Equation (3)) has been proposed. From this work, the following conclusions can be drawn:

1. Compared to other methods, the new method requires specimens of very simple shape (circular cylinders) and very simple dies (flat dies);

2. Neither experimental nor numerical determination of stress components is required at the site of ductile fracture initiation;

3. The friction law's formulation is not required, though the friction stress is the agent for varying the state of stress and strain at the site of ductile fracture initiation;

4. It has been confirmed by comparing the workability diagrams available from the literature and determined in the present paper that the new method is reliable (Figure 6);

5. The new method covers the range of the average stress triaxiality between -1 to 0 , approximately (Figure 6). It can be combined with specimens of various geometric shapes to extend this range. This will be the subject of a subsequent investigation.

Author Contributions: Formal analysis, D.M. and M.M.; methodology, S.A.; project administration, M.V.; resources, D.M. and M.M.; writing—original draft, D.M., M.M. and S.A.; writing-review and editing, M.V. and L.L. All authors have read and agreed to the published version of the manuscript.

Funding: The support by Ministry of Education, Science and Technological Development of Serbia under the grant BULKSURFACE-359 is greatly appreciated.

Conflicts of Interest: The authors declare no conflict of interest.

\section{References}

1. Cockcroft, M.G.; Latham, D.J. Ductility and the Workability of Metals. J. Inst. Met. 1968, 96, 33-39.

2. Oyane, M.; Sato, T.; Okimoto, K.; Shima, S. Criteria for ductile fracture and their applications. J. Mech. Work. Technol. 1980, 4, 65-81. [CrossRef]

3. Atkins, A.G. Fracture in forming. J. Mater. Process. Technol. 1996, 56, 609-618. [CrossRef]

4. Yang, Z.; Zhao, C.; Dong, G.; Chen, Z.; Sun, Y.; Jia, X. Forming limit prediction of AA7075-T6 sheet based on ductile fracture criterion and the error analysis of parameters calibration. Int. J. Mater. Form. 2021, 14, 341-359. [CrossRef]

5. Li, X.; Yang, W.; Xu, D.; Ju, K.; Chen, J. A new ductile fracture criterion considering both shear and tension mechanisms on void coalescence. Int. J. Damage Mech. 2021, 30, 374-398. [CrossRef]

6. Bao, Y.; Wierzbicki, T. A Comparative Study on Various Ductile Crack Formation Criteria. J. Eng. Mater. Technol. Trans. 2004, 126, 314-324. [CrossRef]

7. Wierzbicki, T.; Bao, Y.; Lee, Y.-W.; Bai, Y. Calibration and evaluation of seven fracture models. Int. J. Mech. Sci. 2005, 47, 719-743. [CrossRef]

8. Vilotic, D.; Alexandrov, S.; Ivanisevic, A.; Milutinovic, M. Reducibility of Stress-Based Workability Diagram to Strain-Based Workability Diagram. Int. J. Appl. Mech. 2016, 8, 1-10. [CrossRef]

9. Reiss, W.; Pöhlandt, K. The Rastegaev upset test-A method to compress large material volumes homogeneously. Exp. Tech. 1986, 10, 20-24. [CrossRef]

10. Alexandrov, S.; Vilotic, D.; Konjovic, Z.; Vilotic, M. An Improved Experimental Method for Determining the Workability Diagram. Exp. Mech. 2013, 53, 699-711. [CrossRef]

11. Sljapic, V.; Hartley, P.; Pillinger, I. Observations on fracture in axi-symmetric and three-dimensional cold upsetting of brass. J. Mater. Process. Technol. 2002, 125-126, 267-274. [CrossRef]

12. Sivaraman, A.; Chakkingal, U. Investigations on workability of commercial purity aluminum processed by equal channel angular pressing. J. Mater. Process. Technol. 2008, 202, 543-548. [CrossRef]

13. Wang, Y.; Yang, S.; Zhou, T.; Hou, L.; Ba, L.; Fautrelle, Y.; Ren, Z.; Zhu, Y.; Li, Z.; Li, X. Microstructure evolution and mechanical behavior of Ni-rich Ni-Mn-Ga alloys under compressive and tensile stresses. J. Mater. Sci. Technol. 2022, 97, 113-122. [CrossRef]

14. Kubík, P.; Šebek, F.; Petruška, J. Notched specimen under compression for ductile failure criteria. Mech. Mater. 2018, 125, 94-109. [CrossRef]

15. Šebek, F.; Park, N.; Kubík, P.; Petruška, J.; Zapletal, J. Ductile fracture predictions in small punch testing of cold-rolled aluminium alloy. Eng. Fract. Mech. 2019, 206, 509-525. [CrossRef] 
16. Alexandrov, S.; Vilotić, D. A study on an effect of geometric singularities on ductile fracture. Eng. Fract. Mech. 2009, 76, 2309-2315. [CrossRef]

17. Vilotic, D.; Alexandrov, S.; Plancak, M.; Movrin, D.; Ivanisevic, A.; Vilotic, M. Material formability at upsetting by V-shape dies. In Proceedings of the 11th International Conference on the Technology of Plasticity 2011, Aachen, Germany, 25-30 September 2011; Steel Research International: New York, NY, USA, 2011; pp. 923-928.

18. Vilotic, D.; Alexandrov, S.; Plancak, M.; Vilotic, M.; Ivanisevic, A.; Kacmarcik, I. Material Formability at Upsetting by Cylin-drical and Flat Dies. In Proceedings of the 14th Metal Forming International Conference, Kraków, Poland, 16-19 September 2012; Steel Research International: New York, NY, USA, 2012; pp. 1175-1178.

19. Alexandrov, S.E.; Vilotic, D.; Lyamina, E.A. Effect of a geometric singularity on a surface on ductile fracture. Russ. Met. 2014, 2014, 44-48. [CrossRef]

20. Kacem, A.; Laurent, H.; Thuillier, S. Influence of experimental boundary conditions on the calibration of a ductile fracture criterion. Eng. Fract. Mech. 2021, 248, 107686. [CrossRef]

21. Silva, C.M.A.; Alves, L.M.; Nielsen, C.V.; Atkins, A.G.; Martins, P.A.F. Failure by fracture in bulk metal forming. J. Mater. Process. Technol. 2015, 215, 287-298. [CrossRef]

22. Vilotić, D.; Plančk, M.; Grbić, S.; Alexandrov, S.; Chikanova, N. An approach to determining the workability diagram based on upsetting tests. Fatigue Fract. Eng. Mater. Struct. 2003, 26, 305-310. [CrossRef]

23. Mai, B.V.; Hancock, G.J.; Nguyen, G.D.; Pham, C.H. Shear yielding and failure of cold-reduced G450 sheet steel. J. Constr. Steel Res. 2021, 185, 106844. [CrossRef]

24. Martins, P.A.F.; Bay, N.; Tekkaya, A.E.; Atkins, A.G. Characterization of fracture loci in metal forming. Int. J. Mech. Sci. 2014, 83, 112-123. [CrossRef]

25. Martínez-Donaire, A.J.; Borrego, M.; Morales-Palma, D.; Centeno, G.; Vallellano, C. Analysis of the influence of stress triaxiality on formability of hole-flanging by single-stage SPIF. Int. J. Mech. Sci. 2019, 151, 76-84. [CrossRef]

26. López-Fernández, J.A.; Centeno, G.; Martínez-Donaire, A.J.; Morales-Palma, D.; Vallellano, C. Stretch-flanging of AA2024-T3 sheet by single-stage SPIF. Thin-Walled Struct. 2021, 160, 107338. [CrossRef]

27. Vujović, V.; Shabaik, A.H. A New Workability Criterion for Ductile Metals. J. Eng. Mater. Technol. 1986, 108, 245-249. [CrossRef] 